\title{
3
}

\section{Valores cooperativos y gestión pública}

\author{
Dr. D. Alfredo Ispizua
}

1. Es encomiable el interés y la preocupación universitaria por mantener vivo el debate sobre valores en el mundo económico empresarial, singularmente de la Economía Social, ahora que cada vez más se habla — quizá no tanto se hace 1 — sobre: fondos éticos y solidarios («inversiones socialmente responsables»; sobre banca ética; en fin, sobre ética y negocios, en general.

Interés de la institución universitaria anteponiendo lo importante a lo urgente, lo que quizá en otros ámbitos ajenos al universitario tenemos más dificultades para llevarlo a la práctica.

$Y$ es de agradecer singularmente desde la perspectiva de la Economía Social en cuanto en ellos radica, en esencia, la identidad (que se desarrolla en el Congreso de Manchester, en 1995, por la $\mathrm{ACl}$, pero que ya se preconizara como reconocimiento del «hecho cooperativo» de las instituciones que la conforman, tanto más cuanto ésta se diluye en determinados planteamientos que niegan el papel motor, principal y exclusivo, que al interés económico se le ha atribuido tradicionalmente, conformando lo que se ha conocido como «homo economicus» y frente al cual se ha postulado, como diferencial, el hombre cooperativo.

Por otra parte, abordar esta cuestión de los valores desde la Administración puede llevar fácilmente a la paráfrasis estéril, sin concreción

1 Así, el artículo publicado en La Vanguardia el 15.04.01, p. 11 del suplemento Dinero: «El dinero rehúye las barreras éticas». Sólo 4.000 ahorradores de los más de 7M que invierten en fondos de inversión eligen fondos éticos o solidarios. Por el contrario, la situación en USA o Francia es distinta: Denis DuPRES et Isabell e GIRED-POTIN: "L'investissement financier éthique gagne la France», Problèmes Economiques, n. 2720, p. 17 y ss. 
práctica, por lo que expondremos no sólo lo que nos parece que la Administración puede hacer sino lo que, con fortuna varia, intenta la vasca en esta materia.

Lo que se pretende aquí, por mi parte, es compartir unas reflexiones con la comunidad universitaria y el movimiento cooperativo sobre esta importante materia.

2. Interesan los valores cooperativos (en un desarrollo tradicional de la cuestión) desde un planteamiento de valorización de las relaciones laborales (lato sensu) y en tal sentido, de promoción de las fórmulas de economía participativa y solidaria, como medio de mejorar cualitativamente lo que se ha venido a denominar el mundo del trabajo, sobre todo.

No es cuestión de examinar aquí el papel de lo público en esta materia, de discutir la posicion de los «minnesotos» o de los postkeynesianos.

Cualesquiera que fueren las posturas y argumentos al respecto, en nuestro caso, para la presente Legislatura, la VII, el Gobierno Vasco ha adquirido el compromiso de:

«tener especialmente en cuenta a las empresas cooperativas y de economía social»

En el mensaje de la $\mathrm{ACl}$ para el presente ejercicio se hace hincapié en que las cooperativas no son un instrumento de política gubernamental.

Para nosotros desde luego, son más bien, objeto de políticas gubernamentales.

Esto es, no resulta indiferente a la Administración el tipo de relaciones económicas que fomenta (aspecto transformador); por lo que no es desde la asepsia axiológica desde donde se aborda este tema; en sintonía por otra parte, con la tradición del papel de la Administración respecto de la Economía Social en nuestro entorno.

$Y$ ello no necesariamente imponiendo (desde arriba) valores sino compartiendo (mediante la participación que haga inducir, en común, valores).

Ante el relativismo ético-moral, también en el ámbito de las relaciones económicas, surge (o se mantiene, según los casos) un tipo organizativo empresarial asentado sobre determinados valores, que ahora descubrimos como modernos (en el sentido que están «de moda»). 
Así, se habla de «Responsabilidad Social de la empresa», en su dimensión interna y externa; responsabilidad que ha asumido y practicado la Economía Social, como elemento de su esencialidad.

Voy a detenerme, brevemente, en una explicación sucinta de este punto para concatenar con las ponencias posteriores, desde otras visiones y perspectivas de los valores.

La vida empresarial requiere una cultura empresarial, con pautas de comportamiento definidas².

Desde nuestra perspectiva, la actuación administrativa en Economía Social, nos referimos a una cultura personal, social y empresarial, formada por valores y principios; a una cultura de colaboración y servicio (frente a otra de conflicto y de beneficio); a una cultura que considera la empresa hoy como una "forma de bien colectivo»; una cultura que en otros ámbitos según afirman algunos, está en crisis.

Una cultura que hemos de contextualizarla en una denominada: «nueva economía».

Ocurre, sin embargo, como afirma ATKINSON, que todo lo relacionado con la nueva economía se ha exagerado ${ }^{3}$ un tanto; se inventan conceptos $^{4}$ que luego se materializan, incluso en medios periodísticos 5 ; así, surgen determinados modismos como «economía glokal» ${ }^{6}$ « «coopetición» (un pretendido híbrido entre cooperación y competención), que desde luego, no dejan de causar una cierta perplejidad.

Una economía, en que tendrá gran peso la microeconomía, la flexibilidad organizacional, el medio ambiente, el equilibrio entre lo público y lo privado, los mercados.

2 Argumentación desarrollada en la inauguración de la Jornada sobre Nuevo Trabajo y Valores Cooperativos, organizada por el Consejo Superior de Cooperativas de Euskadi, el 24.04.04, en Villa Suso. Vitoria-Gasteiz.

3 Anthony B. AtKinson, Director del Nuffield College (Oxford). El País Negocios, 11.02.01; p. 24.

4 Véase la página internet: www.dack.com/web/bullshit.html, que sirve para construir aleatoriamente frases brillantes sobre Nueva Economía.

5 Según un exeditor de Business Week, en: Andy RoBINson: «El capitalismo popular necesita psicoanálisis», Suplemento El Dinero de La Vanguardia, domingo, 01.04.01; p. 7.

6 Intenta expresar la máxima: «think global, act local»: actuar sobre recursos e idiosincrasia locales con una perspectiva global de mercado, mezclada con el concepto de «conocimiento» o «economía del conocimiento» — la «k» de glokal, se refiere a knowledege - 
Y es evidente que esta nueva economía influye, especialmente, sobre el mundo del trabajo y sus valores. Y si allí crea una cierta perplejidad, aquí (en el mundo de los valores) provoca una cierta anxiedad y en ocasiones, una cierta «malaise» (social e individual), sobre todo en los jóvenes ${ }^{7}$.

En este sentido, es claramente verificable un postfordismo, que puede resumirse en incremento de autonomía del trabajador en sus tareas y funciones junto con la asunción de una responsabilidad por su trabajo: una mayor involucración («involvement») en la producción, en su calidad (en aras de una mayor competitividad).

Desde esta perspectiva de la competitividad, también será (está siendo, en realidad) un factor clave la participación de los trabajadores, conectado con modernas técnicas (en boga) de gestión y dirección empresariales.

Pero, habría que preguntar si ello implica también (progresivamente) una mayor involucración en la empresa en sí (en el proyecto empresarial), en el poder de la empresa, en la toma de decisiones empresariales vitales - junto con la participación en los resultados y en la propiedad-.

Por otro lado, surgen los «trabajadores del conocimiento» (al lado de los «manuales»). Se produce una deslaboralización en el denominado primer mundo, consecuencia del paso de una economía de producción a otra del conocimiento. Sin embargo, el problema de fondo sigue siendo viejo y consiste en la posibilidad real de acceso generalizado a ese conocimiento. Paradógicamente, la globalización de ciertos mercados privados (por ejemplo, los sanitarios) provoca la aceleración de la privatización y comercialización del conocimiento (por ejemplo, el de la salud) ${ }^{8}$. Esto nos hace recordar por contraste, una de las máximas más queridas por Arizmendiarrieta y repetida por los fundadores de MCC, «socializar el conocimiento para democratizar el poder».

Además, se desdibuja la frontera entre la vida laboral y la extralaboral y se tiende a una homegeneización de la relación social —sobre la base del tecnicismo informático- que provoca sus excluidos.

\footnotetext{
7 «Age of anxiety», carácter del espíritu de la época. M. EYSKENS, Ministro Belga, en: ¿¿Es el cambio progreso? Iru-Courier, 3/99, p. 4-15.

8 Citado por Mariano AguiRre, en El País, 18.04.01, p. 12, y extraído del estudio de las NNUU «Global public goods», Oxford University Press, 1999.
} 
Con carácter general, se afirma que la flexibilidad que exige la economía (el «nuevo capitalismo») endurece las condiciones de trabajo y hace, por una parte, que se pierdan las raíces ${ }^{9}$ y por otra que se devalúen valores: como la integridad o la confianza en los demás; donde carece de sentido el concepto de interés común y la única razón suficiente sea el interés utilitario del individuo.

Por contra, la Economía Social en general y el cooperativismo en particular, asume y reconoce la utilidad y esencialidad de determinados valores en la práctica económico-empresarial.

En general, en el cooperativismo hay una preocupación inicial y constante en este sentido; que excede de lo puramente pragmático (sin desmerecerlo en absoluto; así, los pioneros y referentes cooperativistas europeos fueron muy pragmáticos).

Además, a largo plazo, la ética es rentable. «El comportamiento ético en los negocios tiene repercursiones económicas que se van a sentir, pronto o tarde, en la organización ${ }^{10}$. Añade solidez y seguridad (en la trayectoria y comportamiento empresariales) ${ }^{11}$. Es decir, aunque sólo fuera por un «management de valores», porque se advirtiera que es algo «útil» (y sólo por eso) ${ }^{12}$, sería necesario.

Pero más allá de una "ética de situación» ${ }^{13}$, de unos «valores posicionales» ${ }^{14}$, los valores (y principios, pautas en que aquellos se concretan) del cooperativismo configuran la identidad de la empresa cooperativa y en consecuencia, determinan su organización y funcionamiento

9 José Antonio Marina: El País Semanal, n. ${ }^{\circ}$ 1266, 31.12.00; p. 53.

10 Conclusiones de Claver Cortes, Enrique y otros en: "Etica empresarial. Implicaciones para la dirección de recursos humanos», Bol. Est. Econ. Deusto, n. ${ }^{\circ} 160$, abril 97, pp. 175-187.

11 Dinisio AranzAdI: "Etica de la empresa y Cooperativismo». Rev. de Estudios Empresariales de Deusto, n. ${ }^{\circ} 103$ (2000/2); p. 12-18.

12 «Necesidad de la ética» frente a la asunción y convencimiento éticos en el comportamiento empresarial, en Niklaus BRANCHSTEN: «¿Qué economía necesita el mundo?», Iru-Courier, 3/00, p. 9 a 12.

13 EYSKENS, en: «¿Es el cambio ...». Sostiene el autor que no se puede «decidir» sobre lo bueno y lo malo y aboga por una desdemocratización de la ética.

14 Traído y adaptado del concepto de «bienes posicionales» del economista británico Fred Hirsch. Los valores cooperativos son genéticos a las organizaciones cooperativas, no son utilizados por el cooperativismo para hallar una oferta diferencial respecto del entorno, una posición distinta. Una vez generalizada, desaparecido lo distinto, desparace lo que añade de valor y carece de interés para el que lo ha implantado con dicha finalidad. 
en el mercado (hacia dentro - respecto de los propios trabajadores, en primer lugar - nace para organizar, empresarialmente, la solidaridad entre los trabajadores) y hacia fuera (en las relaciones del tráfico jurídico empresarial).

Valores que ha venido estudiando la $\mathrm{ACl}$ desde los primeros años de la década de los 90 y han sido fijados, los esenciales por consenso, en Manchester, 1995, proclamándose como tales:

- la autoayuda (ayuda mutua): desarrollo comunitario apoyado en el desarrollo personal (acción conjunta y responsabilidad mutua)

- la responsabilidad: en el establecimiento y vitalidad de la propia organización.

-Democracia: frente al control por los intereses del capital, el cooperativismo proclama la anteposición de la persona - con igualdad esencial: un hombre/un voto-, que implica unos socios informados, formados, con derecho a decidir sobre el futuro de la organización.

- Igualdad (se subsume en el anterior).

-Equidad: en el tratamiento del socio, en su participación en la actividad cooperativa, en su organización y en sus resultados.

-y solidaridad: frente a los intereses individuales (prevalecen los colectivos), sentido de comunidad o colectividad de la cooperativa; solidaridad intracooperativa y extracooperativa.

Incluso a estos valores propios o característicos, ha agregado la $\mathrm{ACl}$ otros que denomina "éticos», "tradicionalmente» observados e inspiradores de determinados movimientos cooperativos; no exclusivos, pero sí «convincentes» de un auténtico cooperativismo:

-la honestidad (calidad, precio)

- apertura (transparencia, información)

— responsabilidad social (cuidado de otros)

Efectivamente, son éstos los que dan sentido a la organización empresarial cooperativa y los que además, soportan las denominadas ventajas cooperativas (79. ${ }^{a}$ Jornada Cooperativa Internacional de la $\mathrm{ACl}, 7 .^{\circ}$ Día Internacional de las Cooperativas de la ONU).

Por todo ello, la Economía Social no puede serle indiferente a los responsables públicos: promoviendo y fortaleciendo la Economía Social, promueven y fortalecen valores y actitudes sociales y políticas que se hallan en la raíz del sistema democrático. 
Así, la Economía Social, además de una forma empresarial, se convierte en escuela de formación en valores (para la vida social, asociativa, local-municipal), muy especialmente:

- del VALOR PARTICIPACION, sobre el que se construye la democracia, como base misma de la democracia.

— Así como el COMPROMISO SOCIAL (en la sociedad y en la empresa).

3. Pero interesa también, estimo (en un planteamiento más novedoso), el cooperativismo, sus valores, su cultura, como modelo de gestión de la res pública.

Cada vez es más amplia la literatura sobre identidades y asimilaciones de la gestión pública con la gestión empresarial ${ }^{15}$.

Nosotros mismos, en la Dirección de Economía Social estamos actualmente inmersos en una Reflexión Estratégica, estableciendo su misión, visión, identificando al "cliente externo e interno», el entorno, realizando el típico DAFO (debilidades, amenazas, fortalezas, oportunidades), etc. Terminología y Metodología propios, como se observa, de la planificación empresarial.

Ocurre sin embargo, más allá de estas herramientas de gestión, que el referente empresarial, útil al «progreso democrático» es, habitualmente, el de la sociedad por acciones y los principios del buen gobierno, básicamente, los propios de la eficacia y eficiencia empresariales (responsabilidad, transparencia, coherencia, eficiencia y eficacia, en terminología de las instituciones europeas), que tienden, como finalidad última, a crear confianza en los inversores y en el mercado en general; como por otra parte, no podría ser de otra forma ya que se diferencian en lo esencial o nuclear: en un caso se sigue la regla «un hombre, un voto» frente a «una acción, un voto» ${ }^{16}$.

Esto es, las democracias parlamentarias y las empresas cooperativas se asimilan en lo esencial: "un hombre, un voto»; esto es, su es-

15 Así, el número 265, de junio de 2001, de la revista Futuribles referido al «buen gobierno» público y privado y a la posibilidad de gestión de lo público con criterios y técnicas experimentadas en lo privado.

16 Yves CANNAC y Michel GODET: "La "bonne gouvernance". L'experiencie des entreprises, son utilité pour la sphère publique», Futuribles, n. ${ }^{\circ} 265$, p. 41-50. 
tructura de poder radica en el mismo principio democrático, que se asienta en el protagonismo radical de la persona, en cuanto tal (diferente del: un dólar = un voto).

Por lo tanto, la tesis que aquí se mantiene es: por qué no considerar como referente empresarial el de la economía social en general y el cooperativo en particular, de forma que se gestione lo público haciendo efectiva, sobre todo, la participación y solidaridad ciudadanas, valores que están en el ADN cooperativo, y que pueden colaborar a un «progreso democrático» real, material.

Entiendo que así se avanza no sólo porque cambia la forma jurídica, sino porque ésta encierra en sí misma, como configuradora de su causa y finalidad, valores materiales y no meramente instrumentales, útiles a la gestión pública.

4. Una participación ciudadana (de la «sociedad civil»), activa, frente a una representatitividad puramente formalista, pasiva, que no se inhiba del compromiso cívico de «tomar parte» (en la medida y por los cauces que posibilita la regulación político-administrativa, en lo público y más allá del voto cuatrianual).

De forma que el ciudadano (comprometido) se convierte en colaborador, en cooperador (más que auditor o supervisor) del gestor público.

Esto no quiere decir, en absoluto, que el gestor público se vea suplantado ni tampoco por eso ve aminorado, obviamente, la responsabilidad de dicha gestión. No se está planteando una sustitución o cambio del rol de unos y otros. Los órganos administrativos deben asumir sus competencias y en función de ellas, decidir lo que estimen se ajusta mejor al bien público. Otra cosa será cómo adopten esa decisión. Quiere decirse que no estamos ante el «riesgo» de privatización, donde los actores privados asumen capacidades regalianas propias de los gobernantes públicos, que les son transferidas progresivamente ${ }^{17}$.

Como sucede con el gestor privado, cuya capacidad de decisión y responsabilidad no decae porque solicite de los trabajadores e incluso de clientes su participación en la mejora de la gestión. Sobre todo

17 Sobre este riesgo, VALASKAKIS, Kimon: «Westphalie II: pour un nouvel ordre mondial», Futuribles, n. ${ }^{\circ} 265 ;$ p. 5 y ss. 
ahora, que se habla, en lugar de directores o jefes, de gestores de equipos, de líderes, de dirección por excepción.

Se trata no sólo de tener en cuenta los intereses y necesidades del "cliente», ciudadano, ${ }^{18}$ sino de que éste participe en su satisfacción, además de por los cauces indirectos formales (elección de representantes de los ciudadanos para el parlamento, elección por éste de los gestores, ejecutivo, cada cuatro años), directamente.

Sólo así podrá asumirse lo público como propio.

Sólo así se tendrá confianza real en los gestores públicos (como sólo lo tienen los trabajadores cuando son escuchados, participan, comparten proyectos). Habrá empatía.

Solo así puede construirse una auténtica «comunidad» (aquí no ya "comunidad de trabajo» en el sentido arizmendiano), cuando se compartan valores comunes (comunidad moral) y esto no se realiza automáticamente a través del cumplimiento normativo (como tampoco se hacen cooperativas, en el sentido indicado, con sólo el ropaje jurídico).

De ahí la necesidad de abrir cauces de participación y debate, que permitan compartir valores, hacerlos comunitarios.

5. La solidaridad intergeneracional y la preocupación por la cohesión social (una cohesión social por convicción y no por coacción), favoreciendo la integración de los excluidos de la sociedad, frente a un mutualismo puntual y distribuidor hacia dentro de los miembros de la riqueza creada, de la aséptica regulación de las normas de convivencia, que desconozca a quienes quedan arrinconados, es otro aspecto importante a resaltar.

Aspecto este en que también se acerca la Economía Social al sector público desdibujando, si bien parcialmente (la sociedad cooperativa no es una sociedad filantrópica), el binomio fines interesados/desinteresados, nítidamente distintos en relación con otras formas jurídicas.

Las cooperativas revisten un interés social, cumplen una función social, reconocida por el mismo legislador (en nuestro caso, el art. 137 de la Ley 4/93, de 24 de junio, de Cooperativas, afirma que los pode-

18 No se trata únicamente, de asegurar una gestión conforme a la voluntad e intereses de la gente, pretensión última del estudio que toma como referente la sociedad por acciones. CANNAC y GODET, op. cit., p. 42. 
res públicos de la CAPV asumen como función de interés social la promoción cooperativa), pudiendo algunas incluso, ser declaradas de utilidad pública (cuando contribuyan de forma especial a promover el interés general de Euskadi).

El compromiso con generaciones futuras está en la raíz de determinadas configuraciones jurídicas, dentro de un modelo de cooperativismo determinado, como es la irrepartibilidad de las reservas, que pretende preservar y compartir la riqueza generada.

6. Por supuesto que existen otros valores de aplicabilidad en el área pública, de carácter complementario de los señalados: información transparente, información real y fluida hacia esa sociedad civil; responsabilidad, etc.

Pero por encima de concretas técnicas y antes de todo, está la formación en una cultura participativa y solidaria, una actitud que se aprende y por lo tanto, ha de enseñarse.

7. En relación con los aspectos prácticos, con la realidad en la Euskadi de hoy, algunos pasos se están dando en el área de gestión pública en materia de cooperativas, intentando configurar partnerships públicos privados para abordar distintos aspectos (normativos, de fomento, etc.), más allá de los procedimientos e instituciones formales (más allá de que se elabore por la Administración e informe la entidad asociativa correspondiente —que ni siquiera es vinculante-; más allá del cumplimiento formal de trámite); poniendo en práctica esa actitud de cooperación (de participación).

8. A modo de conclusión, creemos que la combinación equilibrada de los aspectos sociales y los económicos interesa a la Administración fomentar por una parte, en el ámbito laboral y empresarial vascos y por otra, incorporarla a su propio modelo organizativo.

Interesa para una ética cívica, ciudadana, una ética de las relaciones laborales-empresariales.

Interesan los valores cooperativos como referentes para una gestión pública de la calidad.

Interesa fomentar una «economía de las personas» (hecha por las personas para las personas) a la vez que una «sociedad de personas» 
(más allá de las instituciones) mediante su participación activa en la cosa pública (reactualizando el humanismo clásico «el hombre es la medida de todas las cosas»); tanto más cuanto de la gestión pública se requiere una actuación rápida, flexible y acomodada a las exigencias (constantes) derivadas de interacción e interdependencia tanto políticas como institucionales: valor participación-valor democracia.

Interesa fomentar empresas comprometidas (solidarias) con generaciones futuras, con el entorno social; como interesa también la cohesión social de los ciudadanos (ciudadanos solidarios).

Interesa desarrollar la cultura empresarial de la Economía Social en el ámbito local, como contribución del cooperativismo al desarrollo local (no sólo para la prestación de servicios públicos locales, previsión del legislador del art. 137 de la Ley 4/93): un economía hecha por los locales para los locales; como interesa también el asociacionismo local, fuerte y dinámico, para la participación ciudadana en los asuntos públicos más próximos.

Interesa la Economía Social especialmente (aunque por supuesto no sólo) como respuesta a la inserción de colectivos excluidos y/o desarrollo de actividades desatendidas por la economía ordinaria.

Interesa la autoorganización empresarial de los ciudadanos para obtener además de trabajo, educación, vivienda, crédito, bienes de consumo, etc.

Interesa, en fin, la formación en valores que se practicarán en la empresa o en la comunidad política de la que se forma parte, porque:

- formar en la Economía Social es formar ciudadanos responsables y participativos;

- formar en la Economía Social es educar para la concertación y resolución de conflictos, de forma que los diversos intereses no se contrapongan sino que se compongan;

— formar cooperativistas es, para concluir, formar comunidad, una auténtica comunidad que comparta valores. 